OESOPHAGUS

\title{
Diffusion of cytotoxic concentrations of nitric oxide generated luminally at the gastro-oesophageal junction of rats
}

\author{
K Asanuma, K lijima, H Sugata, S Ohara, T Shimosegawa, T Yoshimura
}

See end of article for authors' affiliations

....................

Correspondence to: Dr K lijima, Division of Gastroenterology, Tohoku University Graduate School of Medicine, 1-1 Seiryo-machi, Aobaku, Sendai 980-8574, Japan; jiiima@int3.med.tohoku. ac.jp

Revised version received 6 April 2005

Accepted for publication 20 April 2005

Published online first 28 April 2005
Background: In humans, high concentrations of nitric oxide are generated luminally at the gastrooesophageal junction through enterosalivary recirculation of dietary nitrate.

Aim: To investigate whether luminal nitric oxide can diffuse into the adjacent digestive tissue and alter tissue integrity.

Methods: We designed an animal model using Wistar rats in which physiological concentrations of nitrite and acidified ascorbic acid were administered separately so that the two reactants first meet to form nitric oxide at the gastro-oesophageal junction. Luminal and tissue concentrations of nitric oxide were measured with an electrode and an electron paramagnetic resonance spectrometer, respectively. Concentrations of glutathione in the tissue were measured as a marker of nitrosative stress.

Results: High concentrations of luminal nitric oxide were generated locally at the gastro-oesophageal junction of nitrite administered rats, reproducing a phenomenon observed in humans. High levels of nitric oxide were also detected largely in the superficial epithelium of the gastro-oesophageal junction. The concentration of tissue glutathione at the gastro-oesophageal junction was significantly lower in nitrite administered rats compared with control rats, whereas that in the distal stomach was similar in the two rat groups.

Conclusions: Using an animal model, this study demonstrated that nitric oxide generated in the lumen diffuses into the adjacent gastric tissue to a substantial degree, leading to localised consumption of glutathione in the tissue. Nitrosative stress induced by this mechanism may be involved in the high prevalence of inflammation and metaplasia, and subsequent development of neoplastic disease at this site.
$\mathrm{N}^{\mathrm{s}}$ itric oxide $(\mathrm{NO})$ is an important radical that mediates a wide range of physiological and pathological events. t is generated at low concentrations by the enzyme constitutive nitric oxide synthase (NOS) to modulate neuromuscular and vascular functions. Higher concentrations are generated by the inducible form of the enzyme as part of the immune and inflammatory response. Sustained generation of NO by inducible NO synthesis has been implicated in the aetiology of the mutagenesis and neoplasia related to chronic inflammation. ${ }^{1-3}$

The highest concentrations of NO occurring in the body are not the result of enzymatic synthesis but rather by chemical reactions within the lumen of the stomach, ${ }^{4-7}$ especially in the most proximal part. ${ }^{8}$ This arises from enterosalivary recirculation of dietary nitrate. Ingested nitrate as an ingredient of food is absorbed from the small intestine, and $25 \%$ of this is taken up by the salivary glands and re-secreted into the mouth. ${ }^{9-13}$ Bacteria on the dorsum of the tongue then reduces about $30 \%$ of this nitrate to nitrite. ${ }^{9-13}$ Under fasting conditions, salivary nitrite concentration is approximately $50 \mu \mathrm{M}$, and this rises to as high as $2 \mathrm{mM}$ after ingesting food with a high nitrate content, such as green lettuce. ${ }^{74}$ When salivary nitrite enters the stomach, the combination of the acidity and ascorbic acid content of the gastric juice converts the nitrite to $\mathrm{NO}^{15-17}$ As this reaction between nitrite and ascorbic acid at acidic $\mathrm{pH}$ is very rapid, ${ }^{18-20}$ the intraluminal concentration of $\mathrm{NO}$ generated by the reaction is expected to be maximal at the gastro-oesophageal (GO) junction and cardia, where the nitrite in saliva first encounters gastric acid. Indeed, this was confirmed by a recent study in healthy volunteers which reported that at these anatomical locations substantial amounts of NO are generated following nitrate ingestion, in some case in excess of $50 \mu \mathrm{M}^{8}$
Enterosalivary recirculation of dietary nitrate is sustained for several hours, ${ }^{7421}$ during which period the adjacent epithelium of the GO junction is exposed to abundant amounts of NO generated in the lumen. Membranes in the tissues are not barriers to the diffusion of NO because of its gaseous and lipophilic properties. ${ }^{22}$ Therefore, NO produced in the lumen should readily diffuse into the surrounding epithelium where it may be accumulated to a level sufficient to exert some influence on the integrity of the tissue. In the present experiment, we developed an animal model in which high concentrations of NO were generated luminally at the GO junction by administration of nitrite plus acidic ascorbic acid. Using this model, we investigated whether these high concentrations of NO could diffuse into the adjacent digestive tissue and, if so, at what level, by means of electron paramagnetic resonance (EPR) spectroscopy. In addition, we also investigated whether diffused NO could cause localised consumption of a major antioxidant, glutathione, as an index of nitrosative stress in the tissue.

\section{METHODS \\ Animals}

Male Wistar rats, weighing approximately $250 \mathrm{~g}$ (CLEA Japan Inc, Tokyo, Japan) were used in all of the experiments. Approval of the Animal Welfare Committee at the institute was obtained for all studies.

Abbreviations: DETC, diethyldithiocarbamate; EPR, electron paramagnetic resonance; GO, gastro-oesophageal; NO, nitric oxide; NOS, nitric oxide synthase 


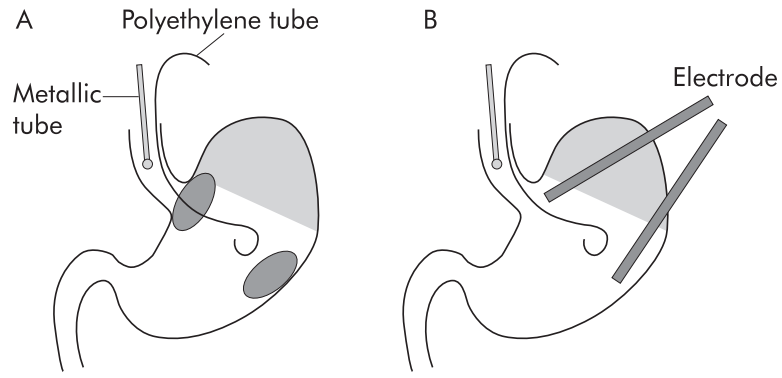

Figure 1 Schematic diagram of the animal model used in this study. (A) Both fine polyethylene and metallic tubes for administrating the reagents described in the text were inserted orally into the rat stomach After each treatment, gastric tissues were obtained from each diagonal area, the gastro-oesophageal (GO) junction, and the distal stomach, and were then employed for various measurements. (B) In other experiments, two electrodes inserted through incisions in the forestomach were placed in the lumen of both the GO junction and the distal stomach to monitor nitric oxide concentrations simultaneously.

\section{The animal model}

A model was developed to simulate the interaction of nitrite swallowed in saliva with gastric hydrochloric acid $(\mathrm{HCl})$ and ascorbic acid in the human gastric lumen, which occurs at the GO junction in humans. ${ }^{8}$

Rats were deprived of food for 24 hours but allowed free access to tap water. They were anaesthetised with an intraperitoneal injection of urethane $(1.25 \mathrm{~g} / \mathrm{kg}$ ) (TokyoKasei, Tokyo, Japan) and were laid supine on a board with their heads elevated at a gradient of $30^{\circ}$. A fine polyethylene tube $(0.61 \mathrm{~mm}$ in diameter; Becton Dickinson, New Jersey, USA) was placed orally in the stomach and was used to administer $10 \mathrm{mM}$ ascorbic acid dissolved in $\mathrm{pH} 2.0 \mathrm{HCl}$ aqueous solution. Another metallic tube $(0.9 \mathrm{~mm}$ in diameter, $50 \mathrm{~mm}$ in length; Natsume, Tokyo, Japan) was inserted orally so that the tip could be placed within the lower part of the rat oesophagus and was used for continuous administration of sodium nitrite aqueous solution (0.5$2 \mathrm{mM}$ ) or water alone as a control, together with $1 \mathrm{mM}$ sodium thiocyanate aqueous solution. Thiocyanate, which is actively secreted in human saliva, is known to be an important catalyst in the chemistry of nitrite under acidic conditions. ${ }^{19}{ }^{23}$ Ascorbic acid solution $(0.5 \mathrm{ml})$ was administered in the stomach, and then infusion of nitrite solution was started at a rate of $0.8 \mathrm{ml} / \mathrm{h}$. The infusion rate of nitrite solution was fixed at this level in all experiments, and corresponded approximately to the delivery rate of human saliva per $\mathrm{kg}$ of body weight. In this model, nitrite administered into the oesophagus was acidified on entering the GO junction and reduced to NO promptly at that site by the reaction with ascorbic acid pooled in the stomach (fig 1). In addition, in another group of rats, famotidine (kindly donated by Yamanouchi Pharmaceutical Co. Ltd, Tokyo, Japan) $(2.5 \mathrm{mg} / \mathrm{kg}$ ) was administered subcutaneously two hours before the experiments and ascorbic acid was prepared with pH 7.4 phosphate buffer, and then the same procedure was repeated.

\section{Luminal NO concentration}

An NO sensor (ISO-NO; WPI Inc., Sarasota, USA) was used for monitoring local concentrations of NO within the gastric lumen in rats. ${ }^{19}{ }^{20}$ The electrode was calibrated by placing it in a solution of $0.1 \mathrm{~mol} / \mathrm{I} \mathrm{H}_{2} \mathrm{SO}_{4} / \mathrm{KI}$ with various concentrations of potassium nitrite. Under urethane anaesthesia, the abdomen was opened by a midline incision and two electrodes were inserted into the gastric lumen via each incision in the forestomach, so that the tips of the electrodes could be placed at the GO junction and at the distal stomach, respectively.
Then, infusion of the test solution was started and concentrations of NO generated in the lumen were monitored by the two electrodes simultaneously at each point (fig l).

\section{Direct measurement of NO by EPR spectrometry}

Concentrations of NO in the gastric tissue of rats were measured using the NO trapping technique combined with EPR spectroscopy. Spin traps react with unstable free radicals such as NO to form a relatively stable radical adduct. This long lived adduct formation results in accumulating a steady state formation of these free radicals, and thus the resultant radical adduct can be detected readily by EPR spectroscopy. Here, we used an Fe-diethyldithiocarbamate (DETC) complex $^{24}{ }^{25}$ as a trapping agent to quantify NO levels in the gastric tissues of rats. ${ }^{26}{ }^{27}$ A DETC $3 \mathrm{H}_{2} \mathrm{O}$ solution $(400 \mathrm{mg} / \mathrm{kg}$; Aldrich Chemical Co., Milwaukee, Wisconsin, USA) and a Fecitrate mixture $\left(40 \mathrm{mg} / \mathrm{kg}\right.$ of $\mathrm{FeSO}_{4} 7 \mathrm{H}_{2} \mathrm{O}$ and $200 \mathrm{mg} / \mathrm{ml}$ of sodium citrate; Wako Pure Chemicals, Osaka, Japan) were injected intraperitoneally and subcutaneously, respectively. Because the Fe-DETC complex formed internally is lipophilic and has a high specificity for $\mathrm{NO}^{25}$ it possesses strong affinity for gastric tissue and an ability to trap NO to form the NO-FeDETC complex, which could be detected by EPR spectroscopy. The concentration in tissues was determined 30 minutes after injection of NO trapping reagent and was expressed as nanomoles per gram of tissue per 30 minutes. ${ }^{25-27}$

Thirty minutes after administration of the trapping reagent, the stomach was removed and the tissue resected selectively from both the GO junction and the distal stomach, the approximate weights of which were 100-120 mg (fig l). Tissue from each area was minced separately and subjected to immediate measurement of NO by EPR spectroscopy. $X$ band $(\sim 9.5 \mathrm{GHz})$ EPR spectra were measured at room temperature with a JEOL TE-200 EPR spectrometer (Tokyo, Japan). Typical instrument settings are shown in the legend to fig 3. In some experiments, $\mathrm{Na}^{15} \mathrm{NO}_{2}\left(99.2 \%{ }^{15} \mathrm{~N}\right.$; Prochem, UK) instead of $\mathrm{Na}^{14} \mathrm{NO}_{2}$ (Sigma, St Louis, Missouri, USA) was used as nitrite. In others, the tissue of the stomach was scratched by a slide glass to separate the mucosa from the muscular layer.

\section{Measurements of reduced glutathione concentration in the tissue}

Nitrite solution (2 $\mathrm{mM})$ or water as a control was injected continuously into the oesophagus over a period of four hours with bolus administration of $0.5 \mathrm{ml}$ of ascorbic acid solution

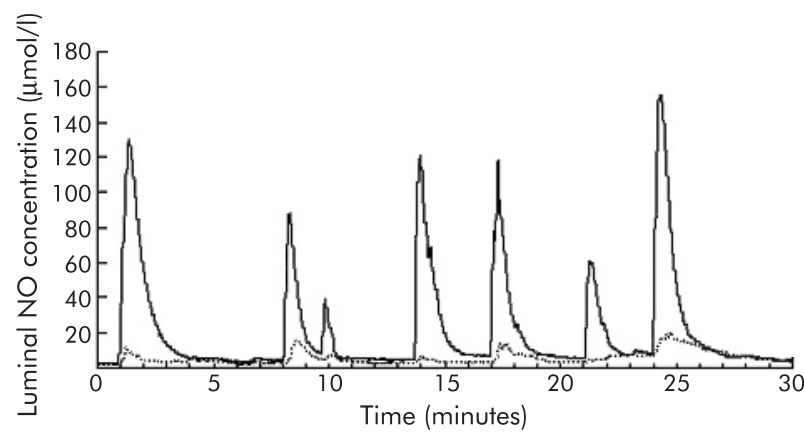

Figure 2 A representative profile of nitric oxide (NO) concentrations monitored simultaneously at the two points within the stomach. After placing $0.5 \mathrm{ml}$ of $10 \mathrm{mM}$ ascorbic acid (pH 2.0) into the stomach, continuous injection of $1 \mathrm{mM}$ sodium nitrite was started at a rate of $0.8 \mathrm{ml} / \mathrm{h}$. Luminal $\mathrm{NO}$ concentrations were monitored by two electrodes at the gastro-oesophageal (GO) junction and distal stomach simultaneously. The solid line represents data from the GO junction and the broken line data from the distal stomach. Generation of luminal NO was considerably higher at the GO junction compared with the distal stomach in this animal model. 


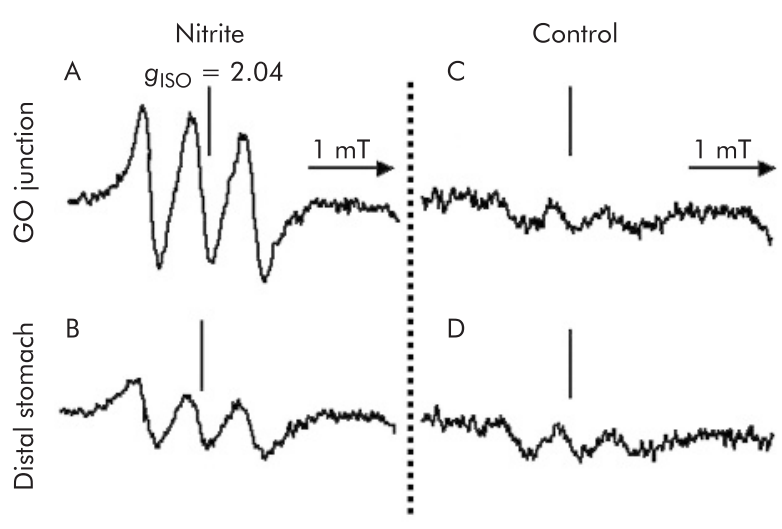

Figure 3 Tracings of the three line spectra at $g=2.04$ to represent the nitric oxide (NO) adduct of the Fe-DETC (NO-Fe-DETC) complex in rat gastric tissue. After placing $0.5 \mathrm{ml}$ of $10 \mathrm{mM}$ ascorbic acid (pH 2.0) into the stomach, continuous injection of $1 \mathrm{mM}$ sodium nitrite or water as a control was started at a rate of $0.8 \mathrm{ml} / \mathrm{h}$. Thirty minutes after administering the NO trapping agent (Fe-DETC), gastric tissue was resected selectively from both the gastro-oesophageal (GO) junction (A, $C)$ and distal stomach (B, D). Signal height is proportional to the amount of NO trapped. The level of the NO-Fe-DETC complex was estimated by comparing it with the signal height of a standard solution of a chemically synthesised NO complex. (A) Electron paramagnetic resonance spectra in the $G O$ junction after nitrite administration; (B) in the distal stomach after nitrite administration; (C) in the GO junction of controls; and (D) in the distal stomach of controls. Instrument settings were as follows: centre field $331 \mathrm{mT}$; field scan $4 \mathrm{mT}$; sweep time two minutes; time constant 0.3 seconds; modulation amplitude $0.32 \mathrm{mT}$; modulation frequency $9.44 \mathrm{GHz}$; and microwave power $60 \mathrm{~mW}$.

(pH 2.0) into the stomach every 30 minutes. Subsequently, the stomach was removed and tissue was resected from similar parts of the stomach, as in the above EPR experiment. Resected tissues were washed in normal saline and weighed. They were minced and homogenised in ice cold metaphosphoric acid solution. Samples were mixed and centrifuged for 10 minutes at $3000 \mathrm{~g}$. The resulting supernatants were used for the assay. Reduced glutathione concentrations were determined by colorimetric assay (Bioxytech GSH-400; OxisResach, USA). ${ }^{28}$

\section{Histology}

At the end of the four hour administration period of $2 \mathrm{mM}$ nitrite solution, as in the above experiment, the stomach was

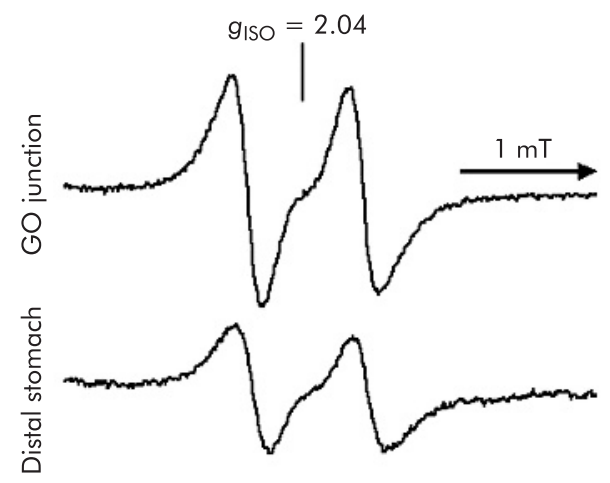

Figure 4 Tracings of two line specta after administration of ${ }^{15} \mathrm{~N}$-nitrite instead of ${ }^{14} \mathrm{~N}$-nitrite in rat gastric tissue. The experimental conditions were similar to those described in fig 3 except that ${ }^{15} \mathrm{~N}$-nitrite was used instead of ${ }^{14} \mathrm{~N}$-nitrite. The characteristic two line electron paramagnetic resonance signal proved that the nitric oxide trapped by the Fe-DETC complex derived from nitrite administered exogenously. Instrument settings were similar to those in fig 3. GO, gastro-oesophageal. removed and opened along the greater curvature. These tissues were fixed in 10\% buffered formalin, embedded in paraffin, and stained with haematoxylin and eosin.

\section{Statistics}

Data are expressed as the mean (SD) of values from five rats in each group. Statistical analyses were performed using a one way analysis of variance followed by the unpaired $t$ test. Values associated with a probability ( $p$ value) of $<0.01$ were considered significant.

\section{RESULTS}

\section{Luminal NO concentration}

High spike peaks of luminal NO were observed intermittently at the GO junction during continuous administration of $1 \mathrm{mM}$ nitrite solution. In the meantime, there were synchronised but much lower peaks of NO detected at the distal stomach (fig 2). Intermittent transit of nitrite into the GO junction due to peristalsis of the oesophagus or transient opening of the GO junction could be responsible for such peaks in the luminal NO concentrations observed during continuous injection of the nitrite solution into the oesophagus. NO generation in the lumen was completely inhibited by maintaining the gastric lumen at neutral $\mathrm{pH}$ with famotidine injection (data not shown).

\section{$X$ band EPR spectroscopy}

A signal with high intensity was observed in $1 \mathrm{mM}$ nitrite administered rats compared with control rats, and was more evident in samples from the GO junction (fig 3). With administration of ${ }^{15} \mathrm{~N}$-nitrite instead of ${ }^{14} \mathrm{~N}$-nitrite, a characteristic two line EPR signal was observed, as shown in fig 4. This splitting of signals originates from the hyperfine interaction of an unpaired electron with the ${ }^{14} \mathrm{~N}(I=1)$ or ${ }^{15} \mathrm{~N}$ nucleus $(I=1 / 2)$ in NO. ${ }^{29}$ This observation proves that NO trapped by the Fe-DETC complex was derived from exogenously administered nitrite. In nitrite administered rats, mean NO level was $1.8(0.2) \mathrm{nmol} / \mathrm{g}$ tissue/per $30 \mathrm{~min}$ utes $(n=5)$ at the GO junction, and was significantly higher than that at the distal stomach. In the same group of rats, manipulation to eliminate acid from the gastric lumen by famotidine administration lowered the NO level to 0.7 (0.3) $(n=5)$ at the GO junction, leading to a level similar to that of the distal stomach (fig 5).

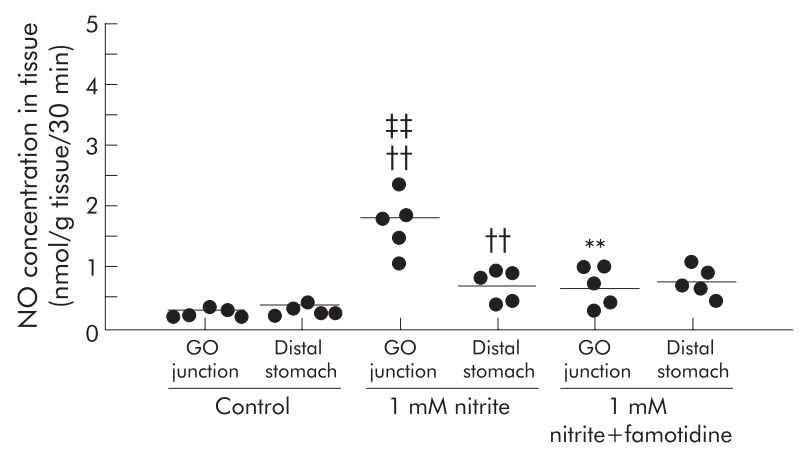

Figure 5 Nitric oxide (NO) concentrations in rat gastric tissue estimated by $\mathrm{X}$ band electron paramagnetic resonance spectrometry. The experimental conditions were similar to those described in fig 3. NO levels were elevated in nitrite administered rats compared with control rats, particularly at the gastro-oesophageal (GO) junction. Famotidine administration abolished the predominance of NO level at the GO junction observed in nitrite administered rats. Mean values of five rats are represented by the horizontal bars. ††Significantly different $(p<0.01)$ from controls; ${ }^{* *}$ from nitrite administration; and $\neq \neq$ from the distal stomach. 


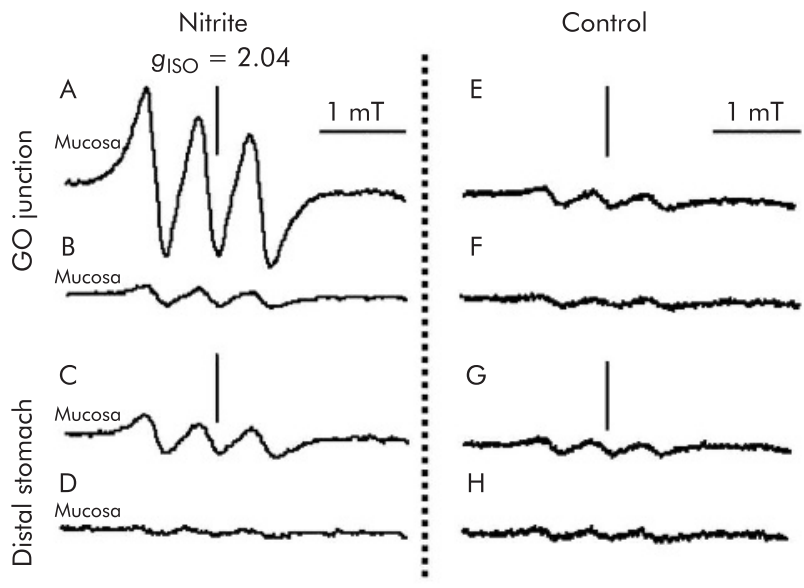

Figure 6 Tracings of electron paramagnetic resonance spectra in the mucosal and muscular layers of the rat stomach. The experimental conditions were similar to those described in fig 3. Samples resected from the gastro-oesophageal (GO) junction and the distal stomach were separated into mucosal and muscular layers, respectively. (A-D) $1 \mathrm{mM}$ nitrite administeration; $(E-H)$ control. ( $A, B, E, F) G O$ junction; ( $C, D, G$, H) distal stomach. (A, C, E, G) Mucosal layer; $(B, D, F, H)$ muscular layer. Instrument settings were similar to those in fig 3 .

The high signal intensity of the NO-Fe-DETC complex was largely confined to the mucosal layer of nitrite administered rats, leaving only a small signal in the inner muscular layers (fig 6). NO level in the mucosal layer increased depending on the concentration of nitrite administered while maintaining the constant distribution of the NO level within the stomach: that of the GO junction was higher than that of the distal stomach. NO level reached up to $6.1(1.0)(n=5)$ in the mucosal layer of the GO junction by administration of $2 \mathrm{mM}$ nitrite. In contrast, NO level in the muscular layer was not affected by administration of nitrite, except for a small increase seen in the GO junction at the highest concentration administered (fig 7). In some DETC experiments with $2 \mathrm{mM}$ nitrite administration, the liver, kidney, and oesophagus were also resected from the rats and subjected to EPR determinations. In these organs, there were no discernible differences in EPR signals compared with the respective controls, suggesting that, because of its lipophilic property, the NOFe-DETC complex did not go into the circulation and remained for at least 30 minutes in the tissue where the complex was formed (data not shown).

In the experiment described above, our samples from the distal stomach consisted of columnar mucosa alone whereas those from the GO junction also contained a small portion of squamous mucosa from the forestomach. Hence an additional experiment was performed using a Lucite chamber system (Tamuraseisakusho, Kyoto, Japan) ${ }^{26}$ to check if the type of gastric mucosa per se could affect the results of estimation of NO levels by EPR spectrometry. Both columnar and squamous mucosa samples were exposed simultaneously to various concentrations of $\mathrm{NO}$ formed in the chamber lumen by the reaction of nitrite and ascorbic acid in the presence of $\mathrm{pH} 2.0 \mathrm{HCl}$. Consequently, NO levels were similar between samples from both types of mucosa, suggesting that NO determination by EPR spectrometry was not influenced by the type of gastric mucosa (data not shown).

\section{Reduced glutathione concentration in tissue}

Four hour exposure to luminal NO generated by continuous infusion of $2 \mathrm{mM}$ nitrite resulted in a significant decrease in the reduced glutathione concentration at the GO junction of rats compared with that of water administered rats as a

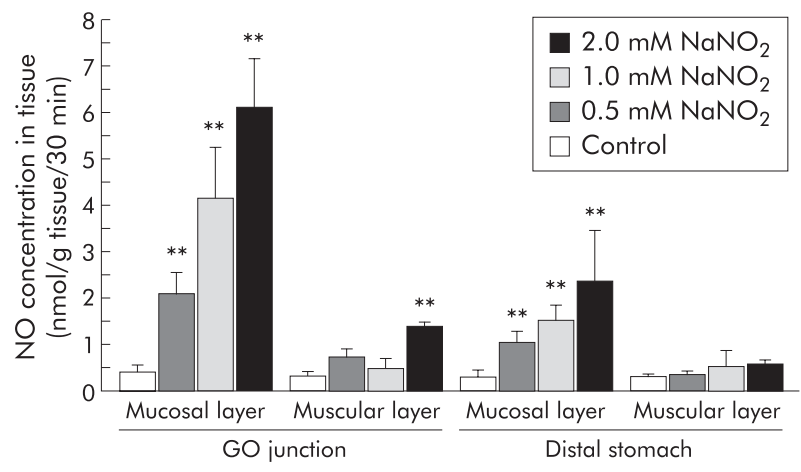

Figure 7 Nitric oxide (NO) concentrations in the mucosal and muscular layers of the rat stomach as a function of the concentration of administered nitrite. The experimental conditions were similar to those described in fig 6 except for the various concentrations $(0-2 \mathrm{mM})$ of sodium nitrite administered. The majority of NO was detected in the superficial mucosal layers from each resected site, with little NO in the inner muscular layers. NO concentrations dose dependently increased as a function of the concentrations of nitrite administered in the mucosal layer of the gastro-oesophageal (GO) junction as well as in that of the distal stomach, although the former was consistently higher than the latter. Values are means (SD) of five rats. ${ }^{* *}$ Significantly different from respective control $(p<0.01)$.
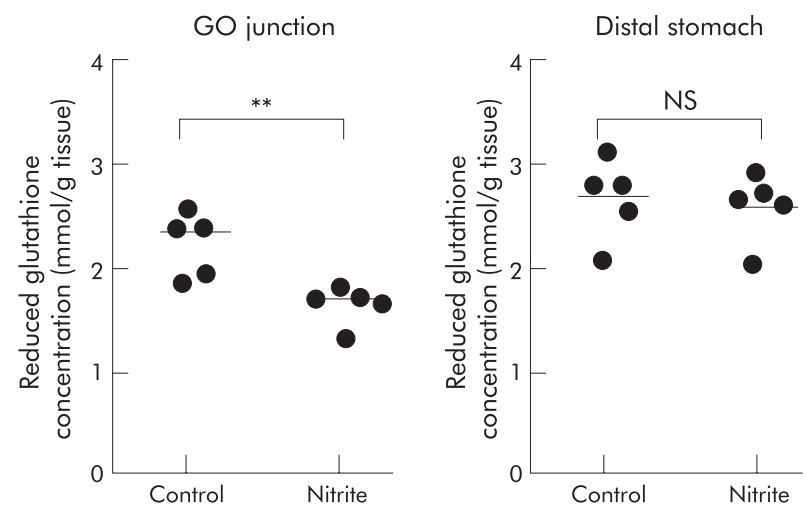

Figure 8 Concentrations of reduced glutathione in gastric tissue resected from the gastro-oesophageal (GO) junction and distal stomach. Sodium nitrite $(2 \mathrm{mM})$ or water as a control was continuously injected over a period of four hours with bolus administration of $0.5 \mathrm{ml}$ ascorbic acid solutiom (pH 2.0) every 30 minutes. Thereafter, tissue was obtained from the same parts of the stomach as in the DETC experiment. Reduced glutathione concentration was decreased by nitrite administration at the GO junction while it remained unchanged at the distal stomach. Mean values of five rats are represented by the horizontal bars. ${ }^{* *} p<0.01$; NS, not significant.

control, while such a change was not observed in the distal stomach (fig 8).

\section{Histology}

Four hour exposure to high levels of luminal NO did not induce any mucosal injury, macroscopically or microscopically, in this animal model.

\section{DISCUSSION}

In the current study, we designed an animal model in which a high level of luminal NO could be formed mainly at the GO junction in order to reproduce the phenomenon observed in humans. ${ }^{8}$ A major finding of this study was that NO generated in the lumen diffused into the adjacent gastric epithelium to a substantial degree, leading to local consumption of reduced glutathione at that site. As we applied a 
concentration of nitrite that has been observed in human saliva after ingestion of a high nitrate meal, this finding may be applicable to the GO junction in humans.

Previous studies demonstrated that at an acidic $\mathrm{pH}$, such as $\mathrm{pH} 1.5$ or 2.5 in the presence of ascorbic acid, most nitrite is converted to NO within a few seconds. ${ }^{18-20}$ In the current animal model, nitrite and acidified ascorbic acid were administered separately so that generation of NO from nitrite could be maximal at the GO junction where the reactants first meet. Elimination of acid from the gastric lumen completely inhibited luminal NO generation in this model, which is consistent with previous reports on the essential role of the presence of acid in the reaction between nitrite and ascorbic acid. ${ }^{18}{ }^{19}$ Using this animal model enabled us to investigate in vivo the influence of NO generated luminally on the integrity of the adjacent gastric tissue.

As NO is known to have dual effects within the tissue (that is, cytoprotective and cytotoxic depending on the gas level) determination of NO level is required to evaluate its function in the tissue. However, from a practical point of view it is difficult to know the actual amounts of NO in the tissue because NO is rapidly metabolised to nitrite, nitrate, or other metabolites and transferred to the circulation. To overcome this difficulty, we applied an EPR spectroscopy technique with an Fe-DETC complex as an NO trapping agent to estimate levels of NO in tissue. ${ }^{25-27}$ By direct measurement of NO concentration in tissue, this technique clearly demonstrated that NO generated in the lumen could actually diffuse into the adjacent gastric tissue. The technique also clarified the distribution of NO within the stomach-that is, the level of gas diffusion into the tissue was higher at the GO junction in our model where nitrite and acidified ascorbic acid first meet to form NO luminally, than at the distal stomach.

In our previous study with EPR spectroscopy, the concentration of NO derived from the constitutive form of NOS in the rat stomach was as small as $0.2-0.3 \mathrm{nmol} / \mathrm{g}$ tissue, ${ }^{26}$ whereas it reached greater than $1.0 \mathrm{nmol} / \mathrm{g}$ tissue when NO was generated by the inducible form of the enzyme in lipopolysaccharide treated rat stomach. ${ }^{27}$ Therefore, the high level of $\mathrm{NO}$ (as high as $6.0 \mathrm{nmol} / \mathrm{g}$ tissue) detected in the mucosal layer at the GO junction in nitrite administered rats was similar to levels derived from inducible NOS, which can induce cytotoxic effects on living cells.

In oxygen containing fluid, NO would react with dissolved oxygen to form the nitrosating species $\mathrm{N}_{2} \mathrm{O}_{3}$, which can be hydrolysed to nitrite. ${ }^{30}$ In the acidic gastric lumen, nitrite thus formed will be rapidly reduced back to NO by ascorbic $\operatorname{acid}^{18-20}$ to maintain the NO concentration. However, once the gas is diffused into the tissue at neutral $\mathrm{pH}$, $\mathrm{NO}$ will be irreversibly converted to nitrite. The rate of NO oxidation is proportional to the square of the NO concentration, ${ }^{31}$ which indicates that the lifetime of NO is inversely proportional to its concentration. This means that, at high concentrations as in the gastric lumen, the half life of NO in the presence of oxygen is less than a second..$^{31}{ }^{32}$ In addition, this reaction is 300 times faster within a hydrophobic media, including the lipid cell membrane, than within an aqueous media because both NO and oxygen are more soluble in the former than in the latter. ${ }^{22}$ Hence the highest concentration of the nitrosating species $\mathrm{N}_{2} \mathrm{O}_{3}$ arising from luminal $\mathrm{NO}$ occurs within the hydrophobic lipid membrane of the superficial epithelial cells and this highly reactive species immediately reacts with surrounding molecules. Consequently, the majority of NO arising from the lumen will be exhausted within the superficial epithelial layer, which is consistent with the current result using EPR spectroscopy in which NO was largely confined to the superficial mucosal layer.

Interestingly, a small but significant amount of NO was detected in the inner muscular layer of the GO junction at the highest concentration of nitrite administered, suggesting that a small portion of $\mathrm{NO}$ arising from the lumen could escape from autoxidation occurring within the superficial layer, reaching the inner tissue. Therefore, the abundant NO formed in the lumen at the GO junction may be sufficient to penetrate the epithelium and then affect the function of the inner smooth muscle cell in the lower oesophageal sphincter. $^{33}$

A high flux of NO arising from the lumen at a sustained concentration could have the potential for causing nitrosative stress on adjacent epithelial cells. The toxicity of NO is largely related to its reaction with oxygen to form higher oxides of nitrogen such as $\mathrm{N}_{2} \mathrm{O}_{3} \cdot{ }^{32}$ Because of the high affinity of $\mathrm{N}_{2} \mathrm{O}_{3}$ for sulfhydrl containing peptides such as glutathione ${ }^{34} 35$ and the abundant contents of glutathione in the gastric tissue, ${ }^{36}$ glutathione can become one of the intracellular targets of NO. In this study, reduced glutathione concentration in tissue was significantly decreased only at a site exposed to high concentrations of luminal NO, suggesting that NO arising from the lumen reacted with glutathione in the adjacent tissue via formation of the intermediate. This is consistent with previous in vitro studies showing that treatment with NO donors caused a decrease in intracellular reduced glutathione level in a variety of cultured cells, ${ }^{37}{ }^{38}$ including a gastric cell line. ${ }^{39}$ Glutathione is known to play a central role as an antioxidant in the protection against cell damage. It has been demonstrated that glutathione deficient cells were more susceptible to the damaging effects of oxidising species ${ }^{40}{ }^{41}$ or to NO mediated cytotoxicity. ${ }^{38}{ }^{39}$ Therefore, the decreased level of reduced glutathione seen in the gastric tissue exposed to high concentrations of luminal NO may render gastric epithelial cells susceptible to oxidative or ongoing nitrosative stress. Although the histological examination of the current study failed to show any histological abnormalities in the gastric tissue after four hours of exposure to NO derived from nitrite, further studies are required to investigate if such treatments could alter the susceptibility of the gastric epithelium to subsequent challenge with luminal irritants such as bile acids. In addition, a long term study is also required to investigate the role of luminal NO generation in epithelial neoplasia. Intriguingly, previous studies have demonstrated that administering nitrite to rats along with ascorbic acid continuously over 50 weeks could induce tumours in the proximal stomach. ${ }^{42-44}$ Luminal NO generation by administration of nitrite plus ascorbic acid may be involved in the mechanism of this tumour induction.

In humans, it has been shown that a high level of salivary nitrite is sustained over several hours after ingestion of a high nitrate meal. ${ }^{7421}$ Nitrite in swallowed saliva has recently been shown to be rapidly converted to $\mathrm{NO}$ at the GO junction. ${ }^{8}$ Using an animal model, we have extended this recent work by showing that a substantial amount of NO actually diffuses from the lumen into the adjacent tissue. Therefore, the human GO junction is likely to be a region of high nitrosative stress. It has been reported in a recent endoscopic study of asymptomatic adults that there was a high incidence (approximately 30\%) of inflammation and intestinal metaplasia, both of which were confined mostly to the GO junction and most proximal cardia region. ${ }^{4-51}$ Nitrosative stress induced by luminal NO generation may be involved in these isolated findings observed in healthy acid secreting stomach, which could also be responsible for the subsequent development of epithelial mutagenesis at this anatomical site.

In conclusion, using an animal model, this study demonstrated that NO generated in the lumen diffuses into the adjacent gastric tissue to a substantial degree at a level comparable with that of inducible NOS derived NO production, leading to local consumption of reduced glutathione in 
the tissue. Nitrosative stress induced by such a mechanism can actually occur in the human body-that is, in the epithelium of the GO junction-and may be involved in the high prevalence of inflammation and metaplasia, and subsequent development of neoplastic disease, at that site.

\section{ACKNOWLEDGEMENTS}

This work was supported in part by a Grant-in-Aid to TY for Scientific Research (15590087) from the Japan Society for the Promotion of Science and for Scientific Research on Priority Areas "Application of Molecular Spins" (15087212) from the Ministry of Education, Culture, Sports, Science, and Technology. This work was also supported in part by a grant to KI from the Japanese Society of Gastroenterology.

\section{Authors' affiliations}

K Asanuma, H Sugata, Laboratory of Applied Biomedicinal Chemistry, Institute for Life Support Technology, Yamagata Promotional Organization for Industrial Technology, Yamagata, Japan, and Division of Gastroenterology, Tohoku University Graduate School of Medicine, Sendai, Miyagi, Japan

K lijima, S Ohara, T Shimosegawa, Division of Gastroenterology, Tohoku University Graduate School of Medicine, Sendai, Miyagi, Japan T Yoshimura, Laboratory of Applied Biomedicinal Chemistry, Institute for Life Support Technology, Yamagata Promotional Organization for Industrial Technology, Yamagata, Japan

Conflict of interest: None declared.

\section{REFERENCES}

1 Oshima $\mathrm{H}$, Bartsch $\mathrm{H}$. Chronic infections and inflammatory processes as cancer risk factors: possible role of nitric oxide in carcinogenesis. Mutat Res 1994;305:253-64.

2 Tamir S, Tannenbaum ST. The role of nitric oxide in the carcinogenesis process. Biochim Biophys Acta 1996;1288:F31-6.

3 Grisham MB, Jourd'heuil D, Wink DA, et al. Physiological chemistry of nitric oxide and its metabolites: implications in inflammation. Am J Physiol 1999;39:G315-21

4 Aneman A, Snygg J, Fandriks L, et al. Continuous measurement of gastric nitric oxide production. Am J Physiol 1996;27:G1039-42.

5 Benjamin N, O'Driscoll F, Dougall H, et al. Stomach NO synthesis. Nature 1994;368:502.

6 Lundberg JON, Weitzberg E, Lundberg JM, et al. Intragastric nitric oxide production in humans: measurements in expelled air. Gut 1994:35:1543-6.

7 McKnight GM, Smith LM, Drummond RS, et al. Chemical synthesis of nitric oxide in the stomach from dietary nitrate in humans. Gut 1997;40:211-14

8 lijima K, Henry E, Moriya A, et al. Dietary nitrate generates potentially mutagenic concentrations of nitric oxide at the gastro-esophageal junction. Gastroenterology 2002;122:1248-57.

9 Walker R. Nitrates, nitrites and $N$-nitroso compounds: a review of the occurrence in food and diet and the toxicological implications. Food Additi Contam 1990:7:717-68.

10 Bos PMJ, van den Brandt PA, Wedel M, et al. The reproducibility of the conversion of nitrate to nitrite in human saliva after a nitrate load. Food Chem Toxic 1988;26:93-7.

11 Wagner DA, Schultz DS, Deen WM, et al. Metabolic fate of an oral dose of ${ }^{15} \mathrm{~N}$-labeled nitrate in humans: Effect of diet supplementation with ascorbic acid. Cancer Res 1983:43:1921-5.

12 Duncan C, Dougall $H$, Johnston $P$, et al. Chemical generation of nitric oxide in the mouth the enterosalivary circulation of dietary nitrate. Nat Med 1995; 1:546-51.

13 Granli T, Dahl R, Brodin P, et al. Nitrate and nitrite concentrations in human saliva: variations with salivary flow-rate. Food Chem Toxic 1989;27:675-80.

14 Pannala A, Mani AR, Spencer JP, et al. The effect of dietary nitrate on salivary, plasma, and urinary nitrate metabolism in humans. Free Radic Biol Med 2003;34:576-84.

15 Mirvish SS, Wallcave L, Eagen M, et al. Ascorbate-nitrite reaction: possible means of blocking the formation of carcinogenic $\mathrm{N}$-nitroso compounds. Science 1972;177:65-8

16 Mirvish SS. Blocking the formation of $\mathrm{N}$-nitroso compounds with ascorbic acid in vitro and in vivo. Ann N Y Acad Sci 1975;258:175-80.

17 Licht WR, Fox JG, Deen WM, et al. Effect of ascorbic acid and thiocyanate on nitrosation of proline in the dog stomach. Carcinogenesis 1988;9:373-7.

18 Moriya A, Grant J, Williams C, et al. In vitro studies indicate that acid catalysed generation of $\mathrm{N}$-nitroso compounds from dietary nitrate will be maximal at the gastro-oesophageal junction and cardia. Scand J Gastroenterol 2002;37:253-61

19 lijima K, Fyfe V, McColl KEL, et al. Studies of nitric oxide generation from salivary nitrite in human gastric juice. Scand J Gastroenterol 2003:38:246-52

20 lijima K, Grant J, McElory K, et al. Novel mechanism of nitrosative stress from dietary nitrate with relevance to gastro-esophageal junction cancers. Carcinogenesis 2003;24:1951-60
21 Mowat C, Carswell A, Wirz A, et al. Omeprazole and dietary nitrate independently affect levels of Vitamin $\mathrm{C}$ and nitrite in gastric juice. Gastroenterology 1999;116:813-22

22 Liu X, Miller MJS, Joshi MS, et al. Accelerated reaction of $\mathrm{NO}$ with $\mathrm{O}_{2}$ within the hydrophobic interior of biological membranes. Proc Natl Acad Sci U S A 1998;95:2175-9.

23 Boyland E, Walker SA. Effect of thiocyanate on nitrosation of amines. Nature 1974;248:601-2.

24 Mordvintcev P, Mulsch A, Busse R, et al. On-line detection of nitric oxide formation in liquid aqueous phase by electron paramagnetic resonance spectroscopy. Anal Biochem 1991;199:142-6.

25 Nagano T, Yoshimura T. Bioimaging of nitric oxide. Chem Rev 2002;102:1235-69.

26 Sugata $H$, Ueno $T$, Shimosegawa $T$, et al. Direct detection of nitric oxide and its roles in maintaining gastric mucosal integrity following ethanol-induced injury in rats. Free Radic Res 2003;37:159-69.

27 Uno K, luchi Y, Fuiii J, et al. In vivo study on cross talk between inducible nitricoxide synthesis and cyclooxygenase in rat gastric mucosa: Effect of cyclooxygenase activity on nitric oxide production. J Pharmacol Exp Ther 2004;309:995-1002

28 Iqbal M, Cohen RI, Marzouk K, et al. Time course of nitric oxide, peroxynitrite, and antioxidants in the endotoxemic heart. Crit Care Med 2002;30:1291-6.

29 Kotake Y. Continuous and quantitative monitoring of rate of cellular nitric oxide generation. Methods Enzymol 1996;268:222-9.

30 Ignarro $\mathrm{J}$, Fukuto JM, Griscavage JM, et al. Oxidation of ntiric oxide in aqueous solution to nitrite but not nitrate: Comparison with enzymatically formed NO from L-arginine. Proc Natl Acad Sci 1993;90:8103-7.

31 Ford PC, Wink DA, Stanbury DM, et al. Autooxidation kinetics of aqueous nitric oxide. FEBS Lett 1993;326:1-3.

32 Wink DA, Fellisch M, Vodovotz $Y$, et al. The chemical biology of nitric oxide. In: Gilbert D L, Coton C A, eds. Reactive oxygen species in biological systems. New York: Kluwer Academic/Plenum Publishers, 1999:245-92.

33 Knudsen MA, Svane D, Tottrup A, et al. Action profiles of NO, S-nitroso-Lcystein, SNP, and NANC responses in opossum lower esophageal sphincter. Am J Physiol 1992;262:G840-6.

34 Kharitonov VG, Sundquist AR, Sharma V, et al. Kinetics of nitrosation of thiols by nitric oxide in the presence of oxygen. J Biol Chem 1995;270:28158-64.

35 Wink DA, Nims RW, Darbyshire JF, et al. Reaction kinetics for nitrosation of cysteine and glutathione in aerobic nitric oxide solutions at neutral $\mathrm{pH}$. Insights into fate and physiological effects of intermediates generated in the $\mathrm{NO} / \mathrm{O}_{2}$ reaction. Chem Res Toxicol 1994;7:519-25.

36 Boyd SC, Sasame HA, Boyd MR, et al. High concentrations of glutathione in glandular stomach: possible implications for carcinogenesis. Science 1979;205:1010.

37 Berendii D, Kolb-Bachofen V, Meyer KL, et al. Influence of nitric oxide on the intracellular reduced clutathione pool: Different cellular capacities and strategies to encounter nitric oxide-mediated stress. Free Radic Biol Med 1999;27:773-80.

38 Luperchio S, Tamir S, Tannenbaum SR, et al. NO-induced oxidative stress and glutathione metabolism in rodent and human cells. Free Radic Biol Med 1996;21:513-19.

39 Wakulich CA, Tepperman BL, et al. Role of glutathione in nitric oxidemediated injury to rat gastric mucosal cells. Eur J Pharmacol 1997:319:333-41.

40 Olson CE. Glutathione modulated toxic oxygen metabolism injury of canine chief cell monolayers in primary culture. Am J Physiol 1988;254:G39-56.

41 Hiraishi H, Terano A, Ota S, et al. Antioxidant defenses of cultured cells against oxygen metabolites: role of GSH redox cycle and endogenous catalase. Am J Physiol 1991;261:G921-8.

42 Yoshida $Y$, Hirose M, Takaba K, et al. Induction and promotion of forestomach tumors by sodium nitrite in combination with ascorbic acid or sodium ascorbate in rats with or without $\mathrm{N}$-methyl- $\mathrm{N}^{\prime}$-nitro- $\mathrm{N}$ nitrosoguanidine pre-treatment. Int J Cancer 1994;56:124-8.

43 Mirvish SS, Pelfrene AF, Garcia H, et al. Effect of sodium ascorbate on tumor induction in rats treated with morpholine and sodium nitrite, and with nitrosomorpholine. Cancer lett 1976;2:101-8.

44 Mirvish SS, Salmasi S, Cohen SM, et al. Liver and forestomach tumors and other forestomach lesions in rats treated with morpholine and sodium nitrite, with and without sodium ascorbate. J Natl Cancer Inst 1983;71:81-5.

45 Oberg S, Peters JH, DeMeester TR, et al. Inflammation and specialized intestinal metaplasia of cardiac mucosa is a manifestation of gastroesophageal reflux disease. Ann Surg 1997;226:522-32.

46 Hacklesberger A, Gunther T, Schultze V, et al. Intestinal metaplasia at the gastro-oesophageal junction: Helicobacter pylori gastritis or gastrooesophageal reflux disease? Gut 1998;43:17-21.

47 Byrne JP, Bhatnagar S, Hamid B, et al. Comparative study of intestinal metaplasia and mucin staining at the cardia and esophagogastric junction in 225 symptomatic patients presenting for diagnostic open-access gastroscopy. Am J Gastroenterol 1999:94:98-103.

48 Nandurkar S, Talley NJ, Martin CJ, et al. Short segment Barrett's oesophagus: prevalence, diagnosis and associations. Gut 1997;40:710-15.

49 Trudgill NJ, Suvarna SK, Kapur KC, et al. Intestinal metaplasia at the squamocolumnar junction in patients attending for diagnostic gastroscopy. Gut 1997:41:585-9.

50 Spechler SJ, Zeroogian JM, Antonioli DA, et al. Prevalence of metaplasia at the gastro-oesophageal junction. Lancet 1994;344:1533-6.

51 Oksanen A, Sipponen P, Karttunen R, et al. Inflammation and intestinal metaplasia at the squamocolumnar junction in young patients with or without Helicobacter pylori infection. Gut 2003;52:194-8. 